Article

\title{
Tunable Silver-Functionalized Porous Frameworks for Antibacterial Applications
}

\author{
Mark A. Isaacs ${ }^{1}$ (D), Brunella Barbero ${ }^{2}$, Lee J. Durndell ${ }^{3}$, Anthony C. Hilton ${ }^{4}$, Luca Olivi 5 (iD, \\ Christopher M. A. Parlett ${ }^{2}$, Karen Wilson ${ }^{6, *}$ and Adam F. Lee ${ }^{6, * \text { (D) }}$ \\ 1 Department of Chemistry, University College London, London WC1H 0AJ, UK; mark.isaacs@ucl.ac.uk \\ 2 European Bioenergy Research Institute, Aston University, Birmingham B4 7ET, UK; \\ brubarbero@gmail.com (B.B.); chrisparlett81@gmail.com (C.M.A.P.) \\ 3 Inorganic Chemistry and Catalysis, Debye Institute for Nanomaterials Science, Utrect University, \\ Universiteitsweg 99, 3584 CG Utrecht, The Netherlands; 1.j.durndell@uu.nl \\ 4 Life and Health Sciences, Aston University, Birmingham B4 7ET, UK; a.c.hilton@aston.ac.uk \\ 5 Sincrotrone Trieste, 34149 Basovizza, Italy; luca.olivi@elettra.eu \\ 6 School of Science, RMIT University, Melbourne, VIC 3001, Australia \\ * Correspondence: karen.wilson2@rmit.edu.au (K.W.); adam.lee2@rmit.edu.au (A.F.L.); \\ Tel.: +61-3-9925-2623 (A.F.L.)
}

Received: 22 June 2018; Accepted: 2 July 2018; Published: 3 July 2018

\begin{abstract}
Healthcare-associated infections and the rise of drug-resistant bacteria pose significant challenges to existing antibiotic therapies. Silver nanocomposites are a promising solution to the current crisis, however their therapeutic application requires improved understanding of underpinning structure-function relationships. A family of chemically and structurally modified mesoporous SBA-15 silicas were synthesized as porous host matrices to tune the physicochemical properties of silver nanoparticles. Physicochemical characterization by transmission electron microscopy (TEM), X-ray diffraction (XRD), X-ray photoelectron spectroscopy (XPS), X-ray absorption near-edge spectroscopy (XANES) and porosimetry demonstrate that functionalization by a titania monolayer and the incorporation of macroporosity both increase silver nanoparticle dispersion throughout the silica matrix, thereby promoting $\mathrm{Ag}_{2} \mathrm{CO}_{3}$ formation and the release of ionic silver in simulated tissue fluid. The $\mathrm{Ag}_{2} \mathrm{CO}_{3}$ concentration within functionalized porous architectures is a strong predictor for antibacterial efficacy against a broad spectrum of pathogens, including C. difficile and methicillin-resistant Staphylococcus aureus (MRSA).
\end{abstract}

Keywords: silver; antibacterial; titania; mesoporous; macroporous; surface functionalization

\section{Introduction}

Healthcare-associated infections (HCAIs) impact on millions of patients annually, and hundreds of thousands of deaths worldwide [1-4]. Current models predict that global mortality rates will approach 10 million annual deaths as a direct result of HCAIs by 2050 [5]. Approximately one-third of all such HCAIs are preventable [6], and while recent improvements in hygiene standards across the medical sector have for example significantly reduced the number of HCAIs per year in the UK, certain groups remain at very high risk of infection during hospital visits, and infection rates for some bacteria such as Escherichia coli have even increased [7-9].

The rise of drug-resistant bacteria which are disproportionately responsible for HCAIs, such as methicillin-resistant Staphylococcus aureus (MRSA) and extended-spectrum beta-lactamases (ESBL)-producing Enterobacteriaceae [2], has prompted a resurgence in the search for broad-spectrum antibiotics to tackle HCAIs. Silver is one such broad spectrum antibiotic, effective against Gram-positive 
(e.g., MRSA, B. subtilis) and Gram-negative bacteria (e.g., E. coli, P. aeruginosa) [10], and is consequently the subject of commercial [11] and academic interest for the treatment of existing HCAIs and drug-resistant organisms through its incorporation in surface coatings [12], nanotechnology [13-16], and pharmaceuticals [17-19].

A major advantage of nanoparticulate silver (and silver-based solid compounds) compared with salts or complexes is that oxidative dissolution is confined to exposed surfaces, offering a potential route to regulate the release of biologically active (commonly held to be $\mathrm{Ag}^{+}$) [20] species permitting the design of long lasting antimicrobial therapies [15,21-23]. Control over silver dissolution kinetics in Ag-nanoparticle-(NP) based systems has been investigated through tuning particle size [23-26], the use of inert coatings to retard release [26], or control of silver speciation in nanocomposite to accelerate dissolution and hence antibacterial activity $[13,14]$. Silver has also shown recent promise as a promoter of conventional antibiotic therapies [27].

Here we explore the use of high surface area and porous metal oxide frameworks to control the dispersion and subsequent dissolution of surface silver. The impact of framework porosity and oxide termination on silver speciation, dissolution, and antibacterical efficacy, was studied using ordered mesoporous and hierarchical macroporous-mesoporous SBA-15 silicas [28,29], and titania functionalized analogues. Conformal titania surface coatings, and hierarchically porous architectures promote silver NP dissolution and activity against Gram-positive (Staphylococcus aureus) and Gram-negative (Pseudomonas aeruginosa) bacteria.

\section{Results and Discussion}

\subsection{Materials Synthesis and Characterisation}

Three families of ordered porous frameworks were prepared using soft or hard-soft dual templating approaches and subsequent titania functionalization (Figure 1). Mesoporous and macroporous-mesoporous (MM) SBA-15 silicas were prepared using a Pluronic 123 (P123) surfactant either alone or in conjunction with $400 \mathrm{~nm}$ colloidal polystyrene nanospheres respectively, according to literature methods. Titania modified variants were subsequently prepared adapting the procedure of Landau et al. [30] to preactivate surface silanols before the self-limited grafting of titanium isopropoxide under anhydrous conditions, and calcination. Repeated grafting cycles were used to create conformal $\mathrm{TiO}_{2}$ monolayers encapsulating the silica supports. Silver nanoparticles were introduced to either the parent SBA-15, or $\mathrm{TiO}_{2}$-grafted SBA-15 and $\mathrm{TiO}_{2}$-grafted MM-SBA-15, frameworks by wet impregnation with varying silver nitrate concentrations.

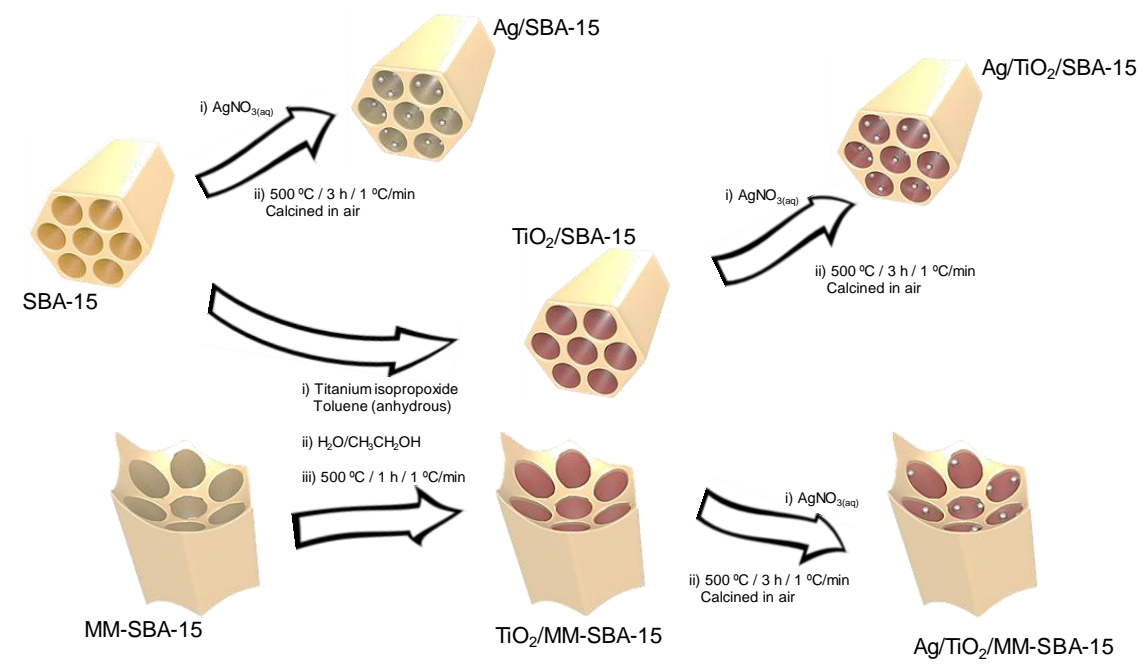

Figure 1. Synthesis of Ag-doped mesoporous silica and titania-functionalized mesoporous and mesoporous-macroporous silica materials. 
Textural properties of the parent SBA-15 and MM-SBA-15 supports, before and after titania functionalization, were first characterized by transmission electronic microscopy (TEM), $\mathrm{N}_{2}$ porosimetry, X-ray diffraction (XRD), and X-ray photoelectron spectroscopy (XPS). The expected hexagonally close-packed channels of the SBA-15 mesopore network were observed in all cases, with surface areas and mesopore diameters decreasing with successive $\mathrm{TiO}_{2}$ grafting cycle (Figure 2 and Figure S1), reflecting pore narrowing and partial blockage of micropores in the silica framework [31]. Uniform mesopores of $6.3 \mathrm{~nm}$ diameter were in accordance with previous reports [29]. No titania crystallites were visible by TEM following grafting, indicating the formation of highly dispersed phase. Assuming a $\mathrm{TiO}_{2}$ monolayer thickness of $0.355 \mathrm{~nm}$ [32], mesopore shrinkage across three grafting cycles from 6.3 to $5.3 \mathrm{~nm}$ for SBA-15 was consistent with deposition of a 1.4 monolayer (ML) titania coating, and from 6 to $5.2 \mathrm{~nm}$ for MM-SBA-15 consistent with 1.1 ML titania.

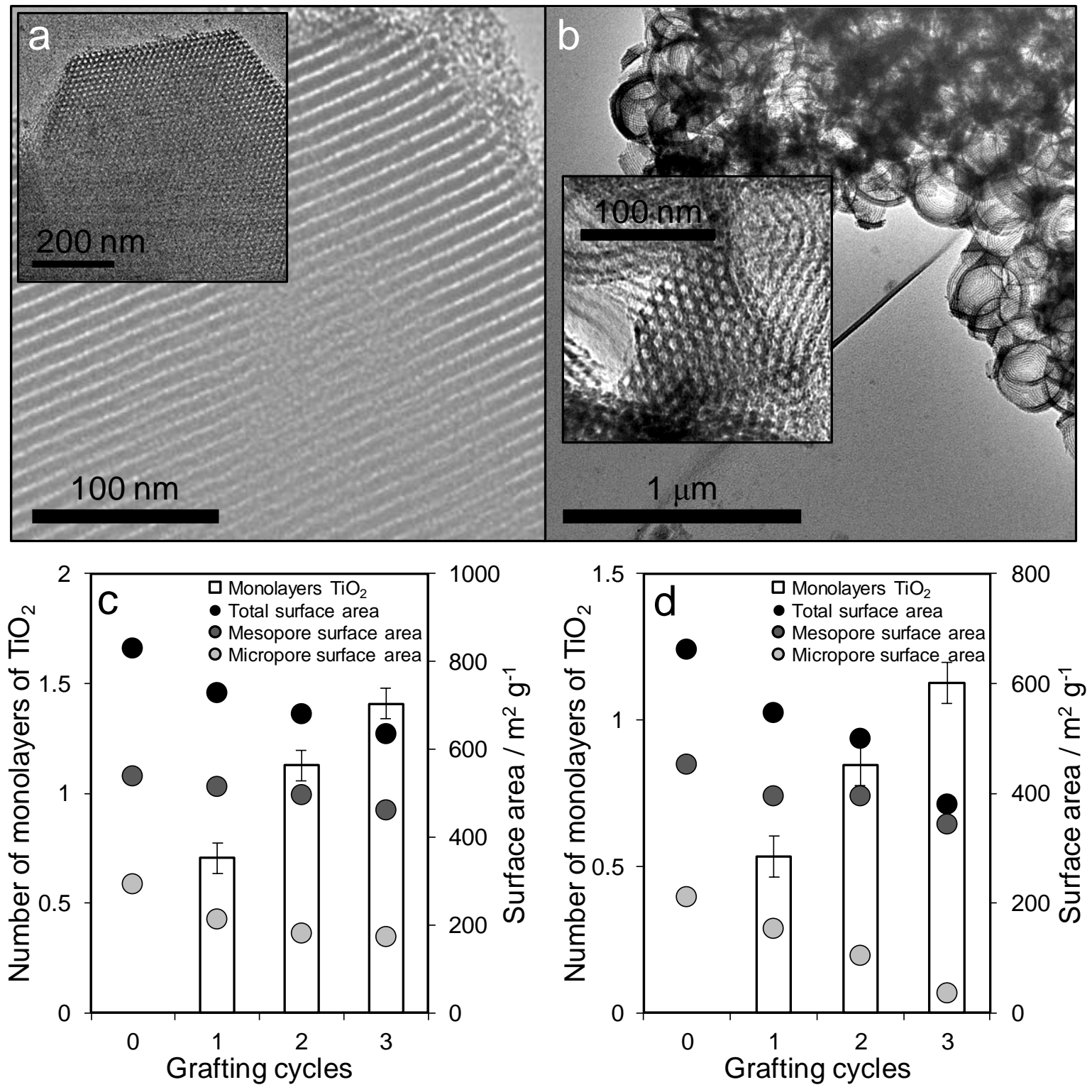

Figure 2. Bright-field transmission electron microscopy (TEM) images of (a) $\mathrm{TiO}_{2} / \mathrm{SBA}-15$ ( $3^{\text {rd }}$ cycle grafting), and (b) $\mathrm{TiO}_{2} / \mathrm{MM}-\mathrm{SBA}-15$ ( $3^{\text {rd }}$ cycle grafting) highlighting ordered hexagonally close-packed mesopores and uniform macropores, and the evolution of textural properties and calculated $\mathrm{TiO}_{2}$ monolayer thickness as a function of grafting cycle for (c) $\mathrm{TiO}_{2} /$ SBA-15 and (d) $\mathrm{TiO}_{2} /$ MM-SBA-15. 
Low-angle X-ray diffraction (XRD) (Figure 3) confirmed that titania-functionalized frameworks retained the P6mm symmetry of the parent SBA-15 mesopore network. Wide angle XRD (Figure S2) showed no evidence for crystalline titania phases, consistent with TEM and the formation of conformal monolayers over the SBA-15 template. The surface chemical environment of Ti atoms within the monolayer coatings was examined by XPS, which reveals the presence of Ti-O-Si (associated with the silica-titania interface) and Ti-O-Ti species over both SBA-15 and MM-SBA-15 with Ti 2 $\mathrm{p}_{5 / 2}$ binding energies of $459.9 \mathrm{eV}$ and $458.5 \mathrm{eV}$ respectively. The shift to higher binding energy for Ti coordinated to $\mathrm{Si}$ (through a bridging oxygen) reflects the higher electronegativity of the latter, and hence higher induced initial charge on the former. We attribute the small shift between the Ti-O-Ti environments in P25 and the titania monolayers to quantum size (initial and/or final state) effects.
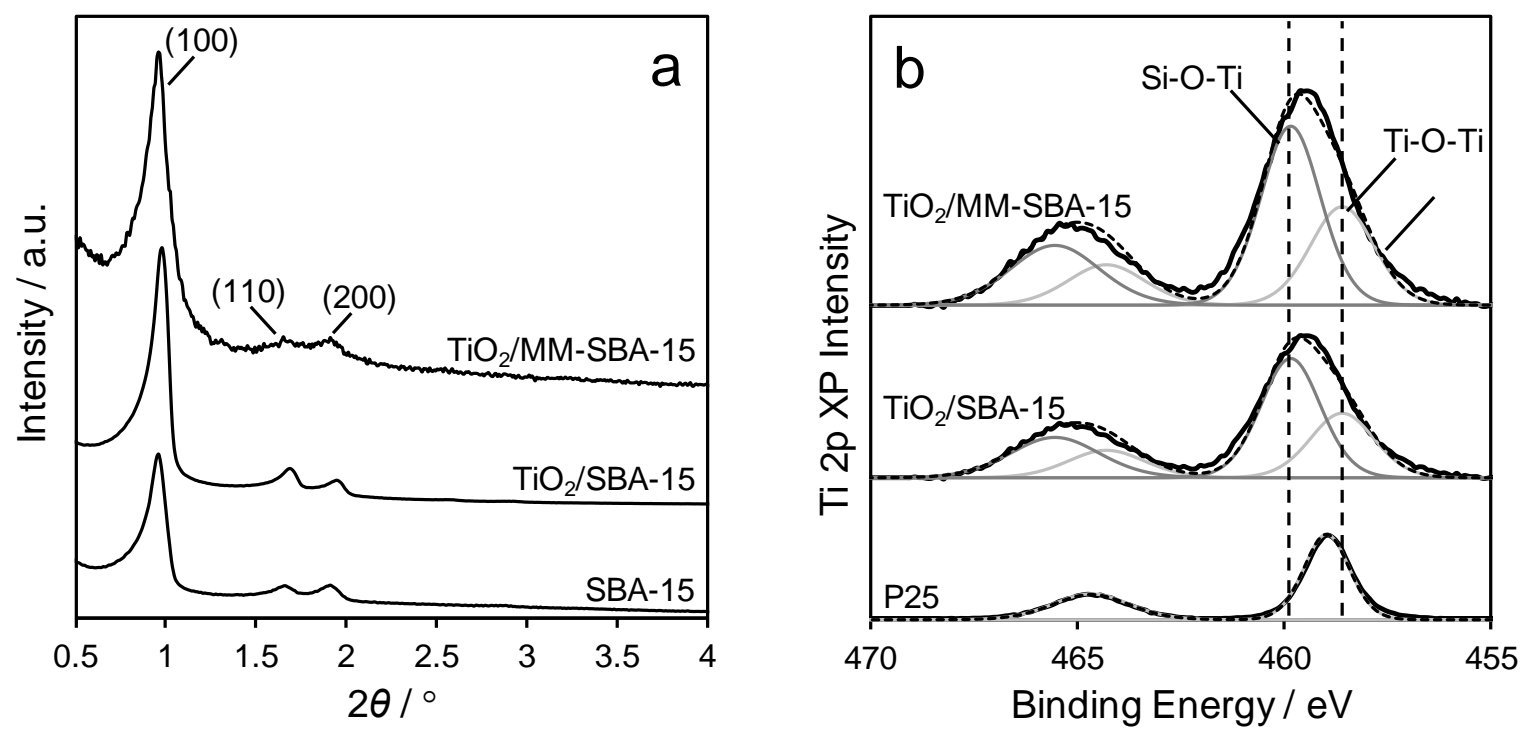

Figure 3. (a) Low angle X-ray diffraction (XRD), and (b) fitted Ti $2 \mathrm{p}$ XP spectra of $\mathrm{TiO}_{2} / \mathrm{SBA}-15$ and $\mathrm{TiO}_{2}$ /MM-SBA-15, alongside pure silica (SBA-15) and titania (P25) references.

Silver was subsequently deposited over the unfunctionalized SBA-15, and $\mathrm{TiO}_{2} / \mathrm{SBA}-15$ and $\mathrm{TiO}_{2} /$ MM-SBA-15 at three different nominal loadings spanning 0.3-3 $\mathrm{wt} \%$ (see the Supplementary Materials (Table S1); elemental analysis revealed almost identical bulk loadings for the mesoporous materials, but systematically lower loadings for the hierarchical material. Surface and bulk silver loadings were generally in good agreement for all materials (see the Supplementary Materials Table S1), indicating a homogenous distribution throughout the porous frameworks. Physicochemical properties of the resulting silver species were determined by TEM, XPS, XRD, and X-ray absorption near edge spectroscopy (XANES). Only fcc metallic silver (JCPDS no. 04-0783) reflections were observed by XRD, which sharpened with increasing loading (see the Supplementary Materials Figure S3), indicative of crystallite growth. Volume averaged silver NP sizes were smaller for MM-SBA-15 (3.5-6.5 nm) than SBA-15 (4.5-8.5 nm) at comparable loadings ( 0.3 wt\%), evidencing higher metal dispersion over the hierarchically porous framework, and indeed fell below the threshold of detection for the lowest $0.25 \mathrm{wt} \% \mathrm{Ag} / \mathrm{TiO}_{2} / \mathrm{MM}-\mathrm{SBA}-15$. Ag NPs were directly visualized by TEM (see the Supplementary Materials Figures S4-S6), which revealed a relatively broad size distribution spanning 1-20 nm over all three supports. The mean particle size increased (and size distribution narrowed) with Ag loading (see the Supplementary Materials Figure S7), with the smallest NPs observed over the hierarchical support in all cases, in accordance with XRD. Ag $3 \mathrm{~d}$ XP spectra showed the existence of two distinct chemical environments with $3 \mathrm{~d}_{5 / 2}$ spin-orbit split component binding energies of $368.0 \mathrm{eV}$ and $370.5 \mathrm{eV}$ consistent with $\mathrm{Ag}^{0}$ and possibly a surface $\mathrm{Ag}_{2} \mathrm{CO}_{3}$ respectively (see the Supplementary Materials Figure S8) [33]. 
Note that discrimination of silver oxides and carbonate by XPS alone is complicated due to their similar core-level binding energies, and anomalous negative binding energy shift of the oxides relative to the metal $[14,34,35]$ and therefore requires careful fitting to well-defined standards (difficult to guarantee due to the tendency of $\mathrm{Ag}_{2} \mathrm{O}$ to oxidise, and of both oxides to adsorb atmospheric $\mathrm{CO}_{2}$ and form surface carbonates [36]), or Auger parameter analysis employing the $\mathrm{Ag} \mathrm{M}_{4,5} \mathrm{NN}$ Auger transition in conjunction with $3 \mathrm{~d}_{5 / 2}$ core-level spectra [13]. Silver speciation as metal, oxide, or carbonate was therefore examined by linear combination fitting of Ag K-edge X-ray absorption near-edge spectroscopy (XANES, see the Supplementary Materials Figures S9-S11). In all cases, good spectral fits could only be obtained using $\mathrm{Ag}$ and $\mathrm{Ag}_{2} \mathrm{CO}_{3}$ components. Nanoparticle growth is accompanied by a continuous decrease in the proportion of surface and bulk silver carbonate for all frameworks (Figure 4). This switchover from electron deficient to metallic silver with particle size likely reflects the higher surface energy of the latter [37], which is thus favoured for larger particles. The bulk $\mathrm{Ag}_{2} \mathrm{CO}_{3}$ content determined by XANES was systematically higher than that of the surface determined by XPS, likely reflecting the distribution of particle sizes present in all materials; XPS is expected to more sensitive to larger (more metallic) particles preferentially located on the external surface. $\mathrm{AgO}$ and $\mathrm{Ag}_{2} \mathrm{O}$ could not be detected by linear combination fitting of the XANES data.

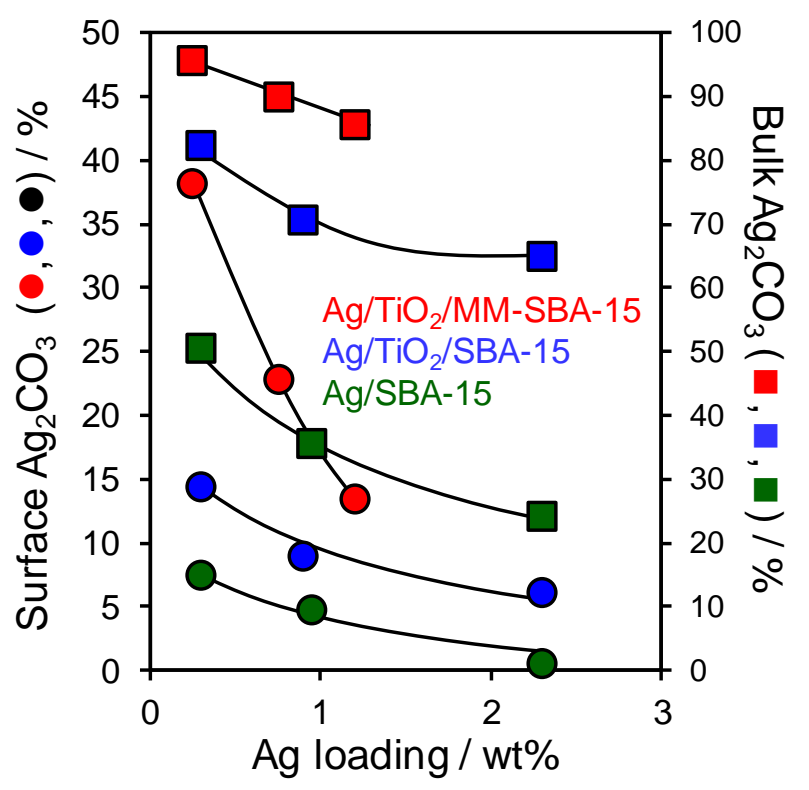

Figure 4. Surface (XPS) and bulk (XANES) silver speciation as $\mathrm{Ag}_{2} \mathrm{CO}_{3}$ of $\mathrm{Ag} / \mathrm{SBA}-15, \mathrm{Ag} / \mathrm{TiO} \mathrm{O}_{2} / \mathrm{SBA}-15$, and $\mathrm{Ag} / \mathrm{TiO}_{2} / \mathrm{MM}-\mathrm{SBA}-15$ as a function of Ag loading.

\subsection{Materials Performance Assaying}

The release rate of ionic silver $\left(\mathrm{Ag}^{+}\right)$from the preceding SBA-15 and MM-SBA-15 frameworks in a $0.5 \mathrm{M} \mathrm{NaNO}_{3}$ solution at $37^{\circ} \mathrm{C}$ was subsequently determined by ICP-MS analysis (Figure 5). Dissolution rates normalised to the mass of silver were inversely proportional to particle size (loading) for all frameworks, as reported for citrate stabilized silver metal nanoparticles [23] and core-shell silver-silica nanoparticles [26] indicating that the release of ionic silver occurred by a common mechanism, being solely dependent on the geometric surface area of the silver nanoparticles. Coating of the mesoporous SBA-15 by a conformal titania monolayer slightly decreased the average particle size over the bare silica framework, and hence increased the rate of silver dissolution, a phenomenon further enhanced by the introduction of macropores. The rate constant for $\mathrm{Ag}^{+}$dissolution was determined as $5244 \mu \mathrm{mol} \cdot \mathrm{h}^{-1} \cdot \mathrm{nm}^{-1} \cdot \mathrm{g}^{1} \mathrm{Ag}$ by fitting the data (see the Supplementary Materials Figure S12) in accordance with the method of Zhang et al. [23] This is significantly higher than that found for $\mathrm{Ag} @ \mathrm{SiO}_{2}$ core-shell nanoparticles $\left(14.7 \mu \mathrm{mol} \cdot \mathrm{h}^{-1} \cdot \mathrm{nm}^{-1} \cdot \mathrm{g}^{-1} \mathrm{Ag}\right)$ [26], while the absolute release rate 
of the $0.3 \mathrm{wt} \% \mathrm{Ag} / \mathrm{TiO}_{2} / \mathrm{MM}-\mathrm{SBA}-15$ is consistent with that previously observed for $0.05 \mathrm{wt} \%$ high surface area Ag-hydroxyapatite nanoparticles [14].

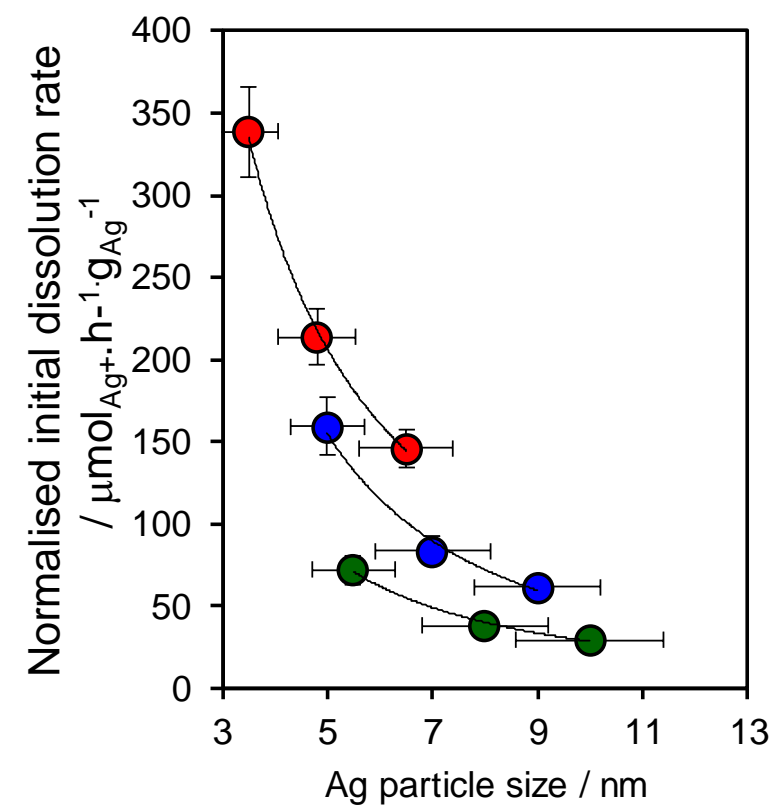

Figure 5. $\mathrm{Ag}^{+}$dissolution rates normalized to mass of Ag determined by XANES for Ag/SBA-15, $\mathrm{Ag} / \mathrm{TiO}_{2} / \mathrm{SBA}-15$ and $\mathrm{Ag} / \mathrm{TiO}_{2} / \mathrm{MM}-\mathrm{SBA}-15$.

Antibacterial activity was subsequently assessed against a range of bacteria (Pseudomonas aeruginosa, Staphylococcus aureus, Clostridium difficile, Escherichia coli, Bacillus subtilis and MRSA) by zone plate inhibition (ZoI) (Figure 6) using simulated body fluid (SBF), in which the antimicrobial efficacy is proportional to the size of the colony-free zone surrounding the silver functionalized porous frameworks. None of the parent (silver-free) materials exhibited bactericidal properties. In all cases the ZoI values normalized to the mass of silver were inversely proportional to silver loading, mirroring the ionic silver release rates, and superior to those reported for hydroxyapatite (HA) supported $\mathrm{Ag}_{3} \mathrm{PO}_{4}$ composites or Ag@SiO 2 core-shell nanocomposites. For example, for S. aureus Ag/ $\mathrm{TiO}_{2} / \mathrm{MM}-\mathrm{SBA}-15$ achieved $70 \mathrm{~mm} \cdot \mathrm{g}_{\mathrm{Ag}}{ }^{-1}$ versus $40-60 \mathrm{~mm} \cdot \mathrm{g}_{\mathrm{Ag}}{ }^{-1}$ for a high area Ag-HA [14] or $23 \mathrm{~mm} \cdot \mathrm{g}_{\mathrm{Ag}}{ }^{-1}$ for $4.5 \mathrm{~nm}$ $\mathrm{Ag}$ nanoparticles encapsulated by a $10.5 \mathrm{~nm}$ mesoporous silica shell) [26]. The zone size (antibacterial performance) decreased in the sequence Ag/ $\mathrm{TiO}_{2} /$ MM-SBA- $15>\mathrm{Ag} / \mathrm{TiO}_{2} / \mathrm{SBA}-15>\mathrm{Ag} / \mathrm{SBA}-15$.

The logarithmic reduction method was also employed to obtain a more quantitative evaluation of antibacterial activity for representative Gram-positive and Gram-negative bacteria (Staphylococcus aureus and Pseudomonas aeruginosa respectively). Experiments were performed in the absence of light to eliminate any possible influence from photogenerated reactive oxygen species by the semiconducting titania coating. All three frameworks were inactive in the absence of silver (see the Supplementary Materials Figure S13). Corresponding decimal reduction times (D-values), i.e., the time to kill $90 \%$ of the bacteria, normalised to the mass of silver, also evidenced an inverse relationship with silver loading for all frameworks (Figure 7) consistent with their $\mathrm{Ag}^{+}$release rates. (Figures S14-S15). As for the ZoI assays, antibacterial activity followed the order $\mathrm{Ag} / \mathrm{TiO}_{2} / \mathrm{MM}-\mathrm{SBA}-15$ $>\mathrm{Ag} / \mathrm{TiO}_{2} / \mathrm{SBA}-15>\mathrm{Ag} / \mathrm{SBA}-15$, i.e., titania functionalization, and the introduction of macroporosity, both enhanced the potency of silver nanoparticles dispersed throughout an SBA-15 framework. $\mathrm{Ag} / \mathrm{MM}-\mathrm{TiO}_{2} / \mathrm{SBA}-15$ outperformed Ag/SBA-15 by $\sim 105 \%$ against Staphylococcus aureus and $\sim 103 \%$ against Pseudomonas aeruginosa. The present observations are consistent with previous reports of augmented antimicrobial efficacy arising from the preferential formation of highly soluble silver carbonate versus silver metal over $\gamma$-alumina supports [13]. 

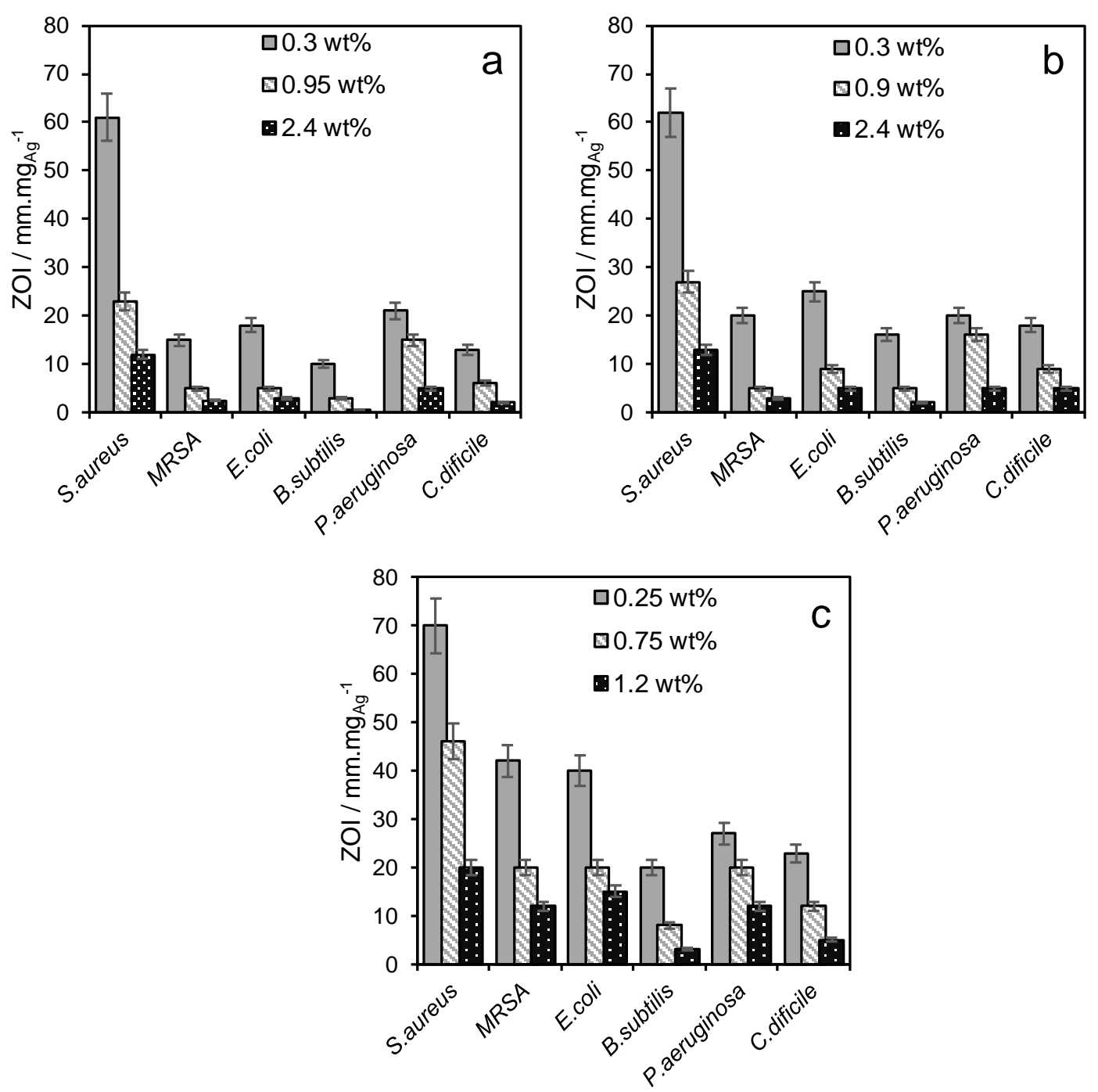

Figure 6. Zone of inhibition plots, normalized to mass of Ag, against a range of Gram-positive and Gram-negative bacteria for (a) Ag/SBA-15, (b) Ag/ $\mathrm{TiO}_{2} / \mathrm{SBA}-15$ and (c) Ag/ $\mathrm{TiO}_{2} / \mathrm{MM}-\mathrm{SBA}-15$.
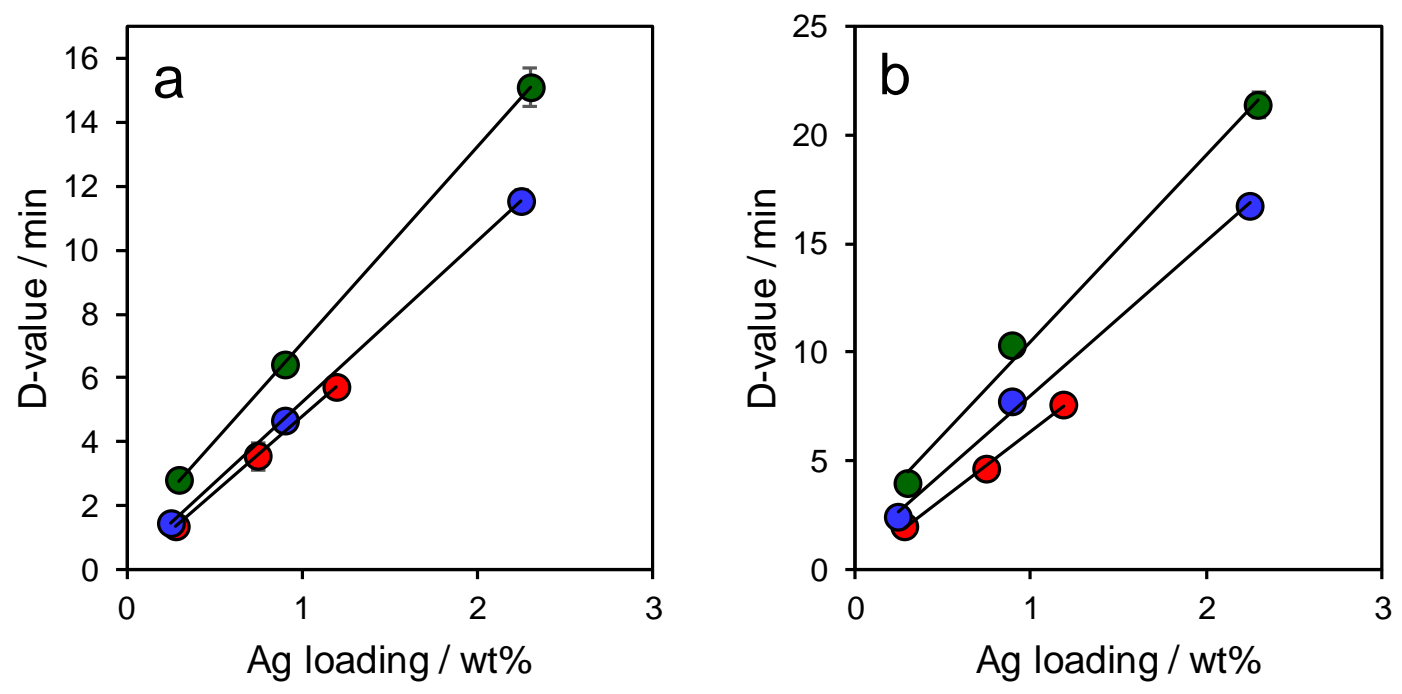

Figure 7. Decimal reduction times for $\mathrm{Ag} / \mathrm{TiO}_{2} / \mathrm{MM}-\mathrm{SBA}-15, \mathrm{Ag} / \mathrm{TiO}_{2} / \mathrm{SBA}-15$ and $\mathrm{Ag} / \mathrm{SBA}-15$ against (a) Staphylococcus aureus, and (b) Pseudomonas aeruginosa. 


\section{Conclusions}

Families of silver functionalized porous frameworks based around surfactant templated SBA-15 mesoporous silica were synthesized to investigate the impact of surface chemistry and pore architecture on antibacterial performance. Silver nanoparticles introduced by wet impregnation of $\mathrm{AgNO}_{3}$ and subsequent thermal processing comprised mixed metal and carbonate phases, with the concentration of silver carbonate (and dissolution rate for ionic $\mathrm{Ag}^{+}$) inversely proportional to particle size independent of the framework. The introduction of a conformal titania monolayer coating of SBA-15 improved the dispersion of silver nanoparticles, corresponding bulk and surface carbonate content, and hence ionic silver release kinetics. This observation likely reflects the ability of defective reducible metal oxides to act as nucleation centers for metals [38-40], thereby increasing the density of small nanoparticles, and amphoteric nature of titania and ability to capture atmospheric $\mathrm{CO}_{2}$ [41] which can subsequently react with (weakly basic) silver oxides [42,43] at the nanoparticle interface. Additional rate enhancements for ionic silver were observed for hierarchical microporous-mesoporous SBA-15 frameworks, presumably due to their stabilization of even smaller silver nanoparticles and hence higher carbonate concentrations. Silver release rates from the porous frameworks directly correlated with broad spectrum antibacterial activity, with a 16-38\% decrease in decimal reduction times for Staphylococcus aureus and Pseudomonas aeruginosa observed following titania functionalization, and a further $65-89 \%$ reduction following the introduction of macroporosity. The quantitative structure-function relationship identified between the concentration of $\mathrm{Ag}_{2} \mathrm{CO}_{3}$ and antibacterial efficacy will guide the development of future nanocomposite architectures, notably optimization of the reducible metal oxide coatings and pore networks to further promote ionic silver release.

\section{Materials and Methods}

Polystyrene bead templates were synthesized using a method developed by Vaudreuil et al. [44] in which styrene, divinyl benzene (comonomer, Sigma Aldrich, 80\%) and potassium persulphate (initiator, Sigma Aldrich, $>99 \%$ ) were the reagents. The reaction was performed on a large scale in a 2-liter jacketed Radleys Reactor-Ready system at $90{ }^{\circ} \mathrm{C}$. Deionized water $(1.5 \mathrm{~L})$ was introduced to the reactor, along with a Leibig condenser, thermocouple, and a nitrogen line at 1.5 bar pressure. The reactor was stirred at $300 \mathrm{rpm}$ overnight to outgas the solution. Styrene $(140 \mathrm{~mL}$, Sigma Aldrich, $>99 \%$ ) and divinylbenzene $(27 \mathrm{~mL})$ were washed with $\mathrm{NaOH}(0.1 \mathrm{M})$ three times in separate separating funnels and added to the reaction vessel. Potassium persulfate (Sigma Aldrich, $0.35 \mathrm{~g}$ ) was dissolved in deionized water $(20 \mathrm{~mL})$ at $80{ }^{\circ} \mathrm{C}$. After $30 \mathrm{~min}$ of stirring $(300 \mathrm{rpm})$ in the reactor at $90{ }^{\circ} \mathrm{C}$, the potassium persulfate solution was added. After stirring for $3 \mathrm{~h}$, the solid particles were recovered as a concentrated solution and stored in a freezer overnight, then the product was allowed to warm before being filtered, washed with ethanol and the beads dried at $80{ }^{\circ} \mathrm{C}$ overnight.

SBA-15 was prepared using a cooperative self-assembly method [29], in which a $2.6 \mathrm{wt} \%$ solution of Pluronic P123 triblock copolymer (poly(ethylene glycol)-poly(propylene glycol)-poly(ethylene glycol) (Sigma Aldrich), in 1.6-M HCl solution was stirred (500 rpm) at $35^{\circ} \mathrm{C}$. Tetraethyl orthoxysilicate (Sigma Aldrich, 98\%) was then added to the mixture, at a molar ratio of 60:1 [TEOS]:[P-123]. The mixture was aged at $80^{\circ} \mathrm{C}$ for $24 \mathrm{~h}$ without stirring in a sealed container in an oven. The resultant solid material was filtered, then washed with ethanol before drying in air at $100{ }^{\circ} \mathrm{C}$ overnight. Removal of the P123 framework was performed by calcination at $500{ }^{\circ} \mathrm{C}$ in a muffle furnace for $6 \mathrm{~h}$ with a ramp rate of $1^{\circ} \mathrm{C} / \mathrm{min}$. Macropores were introduced by the addition of polystyrene beads to the SBA synthesis (2.3.1) at a weight ratio of 5.3:1 [PS beads]:[TEOS] in the initial mixture.

The grafting of titania onto the surface of the prepared silica materials was done using a modified procedure by Landau et al. [30] in which triethylamine is used to activate the surface silanols on the silica and allow the reaction to proceed at lower temperatures. To ensure a uniform coating of $\mathrm{TiO}_{2}$, the reaction must be performed under completely dry conditions, due to the facile hydrolysis of the titania precursor, which will readily form large titania particles in the presence of water. The synthetic procedure involves mixing titanium isopropoxide (Sigma Aldrich,) in anhydrous toluene 
(Aldrich, water content $<0.002 \%$ ), adding triethylamine (Sigma Aldrich, $>99 \%$ ) and MM-SBA-15 or SBA-15 material whilst stirring at $85^{\circ} \mathrm{C}$ for $6 \mathrm{~h}$ under nitrogen flow. The concentration of titanium isopropoxide was $145 \mathrm{~g} / \mathrm{L}$, the molar ratio between titanium isopropoxide and SBA-15 was fixed at 3.5 and the triethylamine: SBA-15 weight ratio at 1.5 on a scale of $5 \mathrm{~g}$ of SBA-15/MM-SBA-15. After the reaction, the solid was separated by filtration, washed with toluene $(300 \mathrm{~mL})$ and inserted in a $0.5 \mathrm{wt} \%$ water-ethanol solution $(500 \mathrm{~mL})$ under stirring for $24 \mathrm{~h}$. The resultant solid was washed with ethanol, dried in air in an oven at $90^{\circ} \mathrm{C}$ for $24 \mathrm{~h}$, then calcined for $1 \mathrm{~h}$ at $250{ }^{\circ} \mathrm{C}, 1 \mathrm{~h} 400{ }^{\circ} \mathrm{C}$ and finally for $4 \mathrm{~h}$ at $500{ }^{\circ} \mathrm{C}$ all at $1^{\circ} \mathrm{C} / \mathrm{min}$.

Ag NPs were deposited via wet impregnation using a solution of aqueous silver nitrate (99.9\%, Sigma-Aldrich). A slurry of the silver precursor and support (10 mL of $5-25 \mu \mathrm{M}+1 \mathrm{~g}$ support) was stirred for $18 \mathrm{~h}$ at room temperature before heating to $50{ }^{\circ} \mathrm{C}$. After $5 \mathrm{~h}$, agitation was ceased and the solid aged at $50{ }^{\circ} \mathrm{C}$ for a further $24 \mathrm{~h}$ to yield a dry powder. Dried samples were calcined at $500{ }^{\circ} \mathrm{C}$ (ramp rate $1^{\circ} \mathrm{C} / \mathrm{min}$ ) in static air for $3 \mathrm{~h}$.

XRD patterns were recorded on either a PANalytical X'pertPro diffractometer fitted with an $X^{\prime}$ celerator detector and $\mathrm{Cu} \mathrm{K} \alpha(1.54 \AA$ ) source or a Bruker D8 Advance diffractometer fitted with a LynxEye high-speed strip detector and $\mathrm{Cu} \mathrm{K} \alpha(1.54 \AA)$ source. Both instruments were calibrated against either Si (PANalytical, Malvern, UK) or $\mathrm{SiO}_{2}$ (Bruker, Billerica, MA, USA) standards. Low angle patterns were recorded for $2 \theta=0.3-8^{\circ}$ with a step size of $0.01^{\circ}$. Wide angle patterns were recorded for $2 \theta=10-80^{\circ}$ with a step size of $0.02^{\circ}$.

$\mathrm{N}_{2}$ adsorption isotherms were recorded using a Nova 4000 porosimeter (Quantachrome, Boynton Beach, FL, USA), before which the samples were thoroughly degassed under vacuum at $120^{\circ} \mathrm{C}$ for $2 \mathrm{~h}$. T-plot analysis was used to calculate microporosity. Data was analyzed using NOVAWin version 11 (Quantachrome, Boynton Beach, FL, USA).

XPS analysis was recorded using a Kratos Axis Hsi X-ray photoelectron spectrometer (Kratos Analytical Ltd., Manchester, UK) using a monochromated Al K $\alpha$ (1486.6 eV) anode. Data was charge corrected to adventitious carbon at $284.6 \mathrm{eV}$ and analyzed using CASAXPS version 2.3.15. Ag 3D peaks were fitted using a Doniach-Sunjic modified Gaussian-Lorentz peak shape and a doublet separation of $6 \mathrm{eV}$.

TEM analysis was performed using a JEOL 2100 microscope (JEOL Ltd., Tokyo, Japan) with a $\mathrm{LaB}_{6}$ source and HT of $180 \mathrm{kV}$. Particle sizing was performed using ImageJ 1.46r software (open source). Samples were prepared using a drop casting method in ethanol onto continuous carbon grids.

Dissolution rates were determined by stirring $10 \mathrm{mg}$ of composite in $25 \mathrm{~mL}$ of $0.5 \mathrm{M} \mathrm{NaNO}_{3}$ at $37^{\circ} \mathrm{C}$ with periodic aliquots of the analyte solution measured for silver content using an Agilent 6130B single Quad (ESI) ICP-MS (Agilent Technologies, Santa Clara, CA, USA) calibrated against a range of silver concentrations made by serial dilution of a $1000 \mathrm{ppm} \mathrm{Ag}$ in $1 \% \mathrm{HNO} 3$ standard from Sigma-Aldrich.

The antibacterial performance of all materials was evaluated against Staphylococcus aureus ATCC 6538, MRSA ATCC 33591, Escherichia coli NCTC 10418, Bacillus subtilis NCTC 8236, Pseudomonas aeruginosa ATCC 15442 and Clostridium difficile ATCC 9689, which are representative Gram-positive and Gram-negative problematic organisms found in hospital environments. Zone of inhibition (ZoI) tests were performed by inoculating the surface of a nutrient agar plate (Oxoid, Basingstoke, UK) with an excess volume $(3 \mathrm{~mL})$ of nutrient broth which had previously been inoculated and incubated to a cell density of $\sim 108$ colony-forming units $(\mathrm{cfu}) / \mathrm{mL}$ as determined spectrophotometrically using a Perkin-Elmer Lambda 10 UV-Vis spectrophotometer. The liquid was manipulated by agitation to provide a confluent inoculum and the excess fluid removed to waste using a sterile pipette. Using a sterilized boring tool, $5 \mathrm{~mm}$ holes were then bored into the agar, and $100 \mu \mathrm{L}$ of a solution of $10 \mathrm{mg}$ of Ag nanocomposite in $5 \mathrm{~mL}$ of simulated body fluid (SBF, see the Supplementary Materials Table S2) dispensed into the borehole using a calibrated micropipette. SBF was prepared according to a method from Kokubo et al. [45] $750 \mathrm{~mL}$ of deionized water was stabilized at $37{ }^{\circ} \mathrm{C}$ with stirring, to this the following ions were added: $\mathrm{NaCl}$ (7.996 g, Sigma Aldrich >99\%), $\mathrm{NaHCO}_{3}(0.35 \mathrm{~g}$, Sigma Aldrich 
$>99 \%), \mathrm{KCl}(0.224 \mathrm{~g}$, Sigma Aldrich $>99 \%), \mathrm{K}_{2} \mathrm{HPO}_{4} \cdot 3 \mathrm{H}_{2} \mathrm{O}$ (0.228 g, Sigma Aldrich $\left.>99 \%\right), \mathrm{MgCl}_{2}$ (0.305 g, Sigma Aldrich >99\%), $\mathrm{HCl}\left(40 \mathrm{~mL}, 1 \mathrm{kmol} / \mathrm{L}\right.$, Fisher scientific 37\%), $\mathrm{CaCl}_{2}$ (0.278 g, Sigma Aldrich >99\%), $\mathrm{Na}_{2} \mathrm{SO}_{4}(0.071 \mathrm{~g}$, Sigma Aldrich $>99 \%)$ and $\left(\mathrm{CH}_{2} \mathrm{OH}\right) 3 \mathrm{CNH}_{2}(6.057 \mathrm{~g}$, Sigma Aldrich $99 \%$. Finally, the $\mathrm{pH}$ was adjusted to 7.35 using $\mathrm{HCl}$ solution $(1 \mathrm{kmol} / \mathrm{L}$, Fisher scientific $37 \%)$. Plates were then incubated at $37^{\circ} \mathrm{C}$ overnight, photographed, and calibrated zone areas determined using ImageJ software (open source).

Quantitative antimicrobial activity was determined by logarithmic reduction [13,14]. Here, $5 \mathrm{mg}$ of Ag nanocomposite material was added to an Eppendorf tube kept in dark conditions containing $1 \mathrm{~mL}$ of either S. aureus or P. aeruginosa in a nutrient broth at concentrations of $107 \mathrm{cfu} \cdot \mathrm{mL}^{-1} .100 \mu \mathrm{L}$ aliquots of the resulting suspensions were subsequently removed at $0,60,240 \mathrm{~min}$ and $24 \mathrm{~h}$, and added to a $1 \mathrm{~mL}$ solution of Tween 20 (Fisher, $1 \%$ ), sodium dodecyl sulphate (Sigma-Aldrich, $0.4 \%$ ) and sodium chloride (Sigma-Aldrich, 0.85\%) in deionized water to neutralise any soluble silver species [13,14].

Each of the resulting neutralized solutions was serially diluted with phosphate buffered saline (PBS) prior to plating onto agar and incubation at $37{ }^{\circ} \mathrm{C}$ for $24 \mathrm{~h}$. The experiments were all run with positive and negative controls of silver nitrate and without any nanocomposite respectively. After incubation, the number of colonies present on the agar was counted by visual inspection, and normalized relative to the initial colony count in the negative control at time $t=0 \mathrm{~min}$ to determine the logarithmic reduction of bacteria. All experiments were performed in triplicate, with mean values and standard deviations reported.

Supplementary Materials: The following are available online at http://www.mdpi.com/2079-6382/7/3/55/s1, Figure S1: (left) $\mathrm{N}_{2}$ adsorption-desorption isotherms, and $\mathrm{BJH}$ pore size distributions for parent SBA-15, $\mathrm{TiO}_{2}$ /SBA-15 and $\mathrm{TiO}_{2}$ /MM-SBA-15. Type-IV isotherms with $\mathrm{H} 1$ hysteresis is characteristic of mesoporous SBA-15, Table S1: Elemental analysis of Ag/SBA-15, Ag/TiO $2 / \mathrm{SBA}-15$ and Ag/ $\mathrm{TiO}_{2} / \mathrm{MM}-\mathrm{SBA}-15$, Figure S2: XRD patterns for the three prepared support materials, SBA-15, $\mathrm{TiO}_{2} / \mathrm{SBA}-15$ and $\mathrm{TiO}_{2} / \mathrm{MM}-\mathrm{SBA}-15$, Figure S3: XRD patterns for (a) Ag/SBA-15; (b) Ag/TiO $2 / \mathrm{SBA}-15$; and (c) Ag/ TiO $2 / \mathrm{MM}-\mathrm{SBA}-15$ as a function of silver loading. All reflections associated with fcc silver metal., Figure S4: Particle size distributions from TEM for (a) $0.3 \mathrm{wt} \%$; (b) $0.95 \mathrm{wt} \%$ and (c) $2.4 \mathrm{wt} \%$ Ag nanoparticles deposited on SBA-15, Figure S5: Particle size distributions from TEM (a) $0.3 \mathrm{wt} \%$; (b) $0.9 \mathrm{wt} \%$ and (c) $2.4 \mathrm{wt} \% \mathrm{Ag}$ nanoparticles deposited on $\mathrm{TiO}_{2} / \mathrm{SBA}-15$, Figure S6: Particle size distributions from TEM (a) $0.25 \mathrm{wt} \%$; (b) $0.75 \mathrm{wt} \%$ and (c) $1.2 \mathrm{wt} \%$ Ag nanoparticles deposited on $\mathrm{TiO}_{2} / \mathrm{MM}-\mathrm{SBA}-15$, Figure S6: Particle size distributions from TEM (a) $0.25 \mathrm{wt} \%$, (b) $0.75 \mathrm{wt} \%$ and (c) $1.2 \mathrm{wt} \% \mathrm{Ag}$ nanoparticles deposited on TiO2/MM-SBA-15, Figure S7: Mean particle size and standard deviation for Ag/SBA-15, Ag/TiO2/SBA-15, and $\mathrm{Ag} / \mathrm{TiO} 2 / \mathrm{MM}-\mathrm{SBA}-15$ as a function of bulk silver loading, Figure S8: Fitted Ag 3d XP spectra of (a) Ag/SBA-15; (b) Ag/ $\mathrm{TiO}_{2} / \mathrm{SBA}-15$; and (c) Ag/ $\mathrm{TiO}_{2} / \mathrm{MM}-\mathrm{SBA}-15$ as a function of Ag loading. All spectra fitted to carbonate and metal spin-orbit doublets possessing common lineshapes and fixed binding energies, Figure S9: XANES profiles for (a) $0.3 \mathrm{wt} \%$; (b) $0.95 \mathrm{wt} \%$ and (c) $2.4 \mathrm{wt} \% \mathrm{Ag} / \mathrm{SBA}-15$, Figure S10: XANES profiles for (a) $0.3 \mathrm{wt} \%$; (b) $0.9 \mathrm{wt} \%$ and (c) $2.4 \mathrm{wt} \% \mathrm{Ag} / \mathrm{TiO}_{2} / \mathrm{SBA}-15$, Figure $\mathrm{S11}$ : XANES profiles for (a) $0.25 \mathrm{wt} \%$; (b) $0.75 \mathrm{wt} \%$ and (c) $1.2 \mathrm{wt} \% \mathrm{Ag} / \mathrm{TiO}_{2} / \mathrm{MM}-\mathrm{SBA}-15$, Figure S12: Fitted dissolution kinetics for Ag/SBA-15, Ag/TiO $2 / \mathrm{SBA}-15$, and $\mathrm{Ag} / \mathrm{TiO}_{2} / \mathrm{MM}-\mathrm{SBA}-15$ as a function of particle size, Figure S13: Zone of Inhibition assays for Staphylococcus aureus, MRSA, Escherichia coli, Bacillus subtilis, Pseudomonas aeruginosa and Clostridium difficile normalized to the mass of silver for (a) Ag/SBA-15; (b) Ag/TiO $2 / \mathrm{SBA}-15$; and (c) Ag/ $\mathrm{TiO}_{2} / \mathrm{MM}-\mathrm{SBA}-15$, Figure S14: Logarithmic reductions for SBA-15, Ag/ $\mathrm{TiO}_{2} / \mathrm{SBA}-15$, and $\mathrm{Ag} / \mathrm{TiO}_{2} / \mathrm{MM}-\mathrm{SBA}-15$ against (a) Staphylococcus aureus and (b) Pseudomonas aeruginosa after $24 \mathrm{~h}$ incubation, Figure S15: Logarithmic reductions for (a) Ag/SBA-15; (b) $\mathrm{Ag} / \mathrm{TiO}_{2} / \mathrm{SBA}-15$; and (c) $\mathrm{Ag} / \mathrm{TiO}_{2} / \mathrm{MM}-\mathrm{SBA}-15$ against Staphylococcus aureus and Pseudomonas aeruginosa, Figure S16: Logarithmic colony forming units of (a) S. aureus; and (b) P. aeruginosa as a function of time for SBA-15, $\mathrm{TiO}_{2} / \mathrm{SBA}-15$, and $\mathrm{TiO}_{2}$ /MM-SBA-15, Table S1: Elemental analysis of Ag/SBA-15, Ag/TiO2/SBA-15 and $\mathrm{Ag} / \mathrm{TiO} 2 / \mathrm{MM}-\mathrm{SBA}-15$, Table S2: Ion concentrations in SBF solution.

Author Contributions: Formal analysis-M.A.I., A.C.H. and A.F.L.; Funding acquisition-K.W. and A.F.L.; Investigation-M.A.I.; Methodology-M.A.I., B.B., A.C.H. and L.O.; Supervision-K.W. and A.F.L.; Visualization-L.J.D. and C.M.A.P.; Writing—original draft, M.A.I.; Writing-review \& editing, A.F.L.

Acknowledgments: We thank the Knowledge Economy Skills Scholarship (K.E.S.S.) program and Polymer Health Technology for providing funding for this work.

Conflicts of Interest: The authors declare no conflicts of interest. 


\section{References}

1. Zarb, P.; Coignard, B.; Griskeviciene, J.; Muller, A.; Vankerckhoven, V.; Weist, K.; Goossens, M.; Vaerenberg, S.; Hopkins, S.; Catry, B. The European Centre for Disease Prevention and Control (ECDC) pilot point prevalence survey of healthcare-associated infections and antimicrobial use. Eurosurveillance 2012, 17, 20316. [CrossRef] [PubMed]

2. Hansen, S.; Schwab, F.; Zingg, W.; Gastmeier, P. Process and outcome indicators for infection control and prevention in European Acute Care Hospitals in 2011 to 2012-results of the prohibit study. Eurosurveillance 2018, 23, 1700513. [CrossRef] [PubMed]

3. Cassini, A.; Plachouras, D.; Eckmanns, T.; Sin, M.A.; Blank, H.-P.; Ducomble, T.; Haller, S.; Harder, T.; Klingeberg, A.; Sixtensson, M. Burden of six healthcare-associated infections on european population health: Estimating incidence-based disability-adjusted life years through a population prevalence-based modelling study. PLoS Med. 2016, 13, e1002150. [CrossRef] [PubMed]

4. Modic, M.; Nikiforov, A.; Leys, C.; Kuchakova, I.; De Vrieze, M.; Petrovska, M.; Zille, A.; Dinescu, G.; Mitu, B.; Cvelbar, U. Atmospheric Pressure Plasma and Depositions of Antibacterial Coatings; Meeting Abstracts; The Electrochemical Society: Pennington, NJ, USA, 2018; p. 1176.

5. O'Neill, J. Antimicrobial resistance: Tackling a crisis for the health and wealth of nations. Rev. Antimicrob. Resist. 2014, 1-20. Available online: https://amr-review.org/sites/default/files/AMR\%20Review\% 20Paper $\% 20$ - $\%$ 20Tackling $\% 20$ a $\% 20$ crisis $\% 20$ for $\% 20$ the $\% 20$ health $\% 20$ and $\% 20$ wealth $\% 20$ of $\% 20$ nations_1. pdf (accessed on 28 June 2018).

6. Peleg, A.Y.; Hooper, D.C. Hospital-acquired infections due to gram-negative bacteria. N. Engl. J. Med. 2010, 362, 1804-1813. [CrossRef] [PubMed]

7. Service, N.H. Clostridium Difficile, Staphylococcus Aureus Bacteraemia and Escherichia coli Bacteraemia, Surveillance Update. Available online: https:/ / www.wales.nhs.uk/sites3/page.cfm?orgid=379\&pid=67899 (accessed on 30 May 2018).

8. England, P.H. Annual Epidemiological Commentary Mandatory MRSA, MSSA and E. coli Bacteraemia and C. difficile Infection Data 2016/17. Available online: https:/ / assets.publishing.service.gov.uk/government/ uploads/system/uploads/attachment_data/file/634675/Annual_epidemiological_commentary_2017. pdf (accessed on 2 July 2018).

9. Bhattacharya, A.; Nsonwu, O.; Johnson, A.; Hope, R. Estimating the incidence and 30-day all-cause mortality rate of Escherichia coli bacteraemia in England by 2020/21. J. Hosp. Infect. 2018, 98, 228-231. [CrossRef] [PubMed]

10. Percival, S.L.; Bowler, P.G.; Dolman, J. Antimicrobial activity of silver-containing dressings on wound microorganisms using an in vitro biofilm model. Int. Wound J. 2007, 4, 186-191. [CrossRef] [PubMed]

11. Furr, J.R.; Russell, A.D.; Turner, T.D.; Andrews, A. Antibacterial activity of actisorb plus, actisorb and silver nitrate. J. Hosp. Infect. 1994, 27, 201-208. [CrossRef]

12. Textor, T.; Fouda, M.M.; Mahltig, B. Deposition of durable thin silver layers onto polyamides employing a heterogeneous tollens' reaction. Appl. Surf. Sci. 2010, 256, 2337-2342. [CrossRef]

13. Buckley, J.J.; Gai, P.L.; Lee, A.F.; Olivi, L.; Wilson, K. Silver carbonate nanoparticles stabilised over alumina nanoneedles exhibiting potent antibacterial properties. Chem. Commun. 2008, 4013-4015. [CrossRef] [PubMed]

14. Buckley, J.J.; Lee, A.F.; Olivi, L.; Wilson, K. Hydroxyapatite supported antibacterial $\mathrm{Ag}_{3} \mathrm{Po}_{4}$ nanoparticles. J. Mater. Chem. 2010, 20, 8056-8063. [CrossRef]

15. Lee, Y.-J.; Kim, J.; Oh, J.; Bae, S.; Lee, S.; Hong, I.S.; Kim, S.-H. Ion-release kinetics and ecotoxicity effects of silver nanoparticles. Environ. Toxicol. Chem. 2012, 31, 155-159. [CrossRef] [PubMed]

16. Luo, S.; Chen, J.; Chen, M.; Xu, W.; Zhang, X. Antibacterial activity of silver nanoparticles colloidal sol and its application in package film. Adv. Mater. Res. 2012, 380, 254-259. [CrossRef]

17. Ray, S.; Mohan, R.; Singh, J.K.; Samantaray, M.K.; Shaikh, M.M.; Panda, D.; Ghosh, P. Anticancer and antimicrobial metallopharmaceutical agents based on palladium, gold, and silver N-Heterocyclic carbene complexes. J. Am. Chem. Soc. 2007, 129, 15042-15053. [CrossRef] [PubMed]

18. Patil, S.; Deally, A.; Gleeson, B.; Müller-Bunz, H.; Paradisi, F.; Tacke, M. Novel benzyl-substituted N-Heterocyclic carbene-silver acetate complexes: Synthesis, cytotoxicity and antibacterial studies. Metallomics 2011, 3, 74-88. [CrossRef] [PubMed] 
19. Almalioti, F.; MacDougall, J.; Hughes, S.; Hasson, M.M.; Jenkins, R.L.; Ward, B.D.; Tizzard, G.J.; Coles, S.J.; Williams, D.W.; Bamford, S. Convenient syntheses of cyanuric chloride-derived NHC ligands, their Ag (I) and Au (I) complexes and antimicrobial activity. Dalton Trans. 2013, 42, 12370-12380. [CrossRef] [PubMed]

20. Kumar, R.; Münstedt, H. Silver ion release from antimicrobial polyamide/silver composites. Biomaterials 2005, 26, 2081-2088. [CrossRef] [PubMed]

21. Liu, J.; Hurt, R.H. Ion release kinetics and particle persistence in aqueous nano-silver colloids. Environ. Sci. Technol. 2010, 44, 2169-2175. [CrossRef] [PubMed]

22. Zhao, X.; Xia, Y.; Li, Q.; Ma, X.; Quan, F.; Geng, C.; Han, Z. Microwave-assisted synthesis of silver nanoparticles using sodium alginate and their antibacterial activity. Colloids Surf. A Physicochem. Eng. Asp. 2014, 444, 180-188. [CrossRef]

23. Zhang, W.; Yao, Y.; Sullivan, N.; Chen, Y. Modeling the primary size effects of citrate-coated silver nanoparticles on their ion release kinetics. Environ. Sci. Technol. 2011, 45, 4422-4428. [CrossRef] [PubMed]

24. Peretyazhko, T.S.; Zhang, Q.; Colvin, V.L. Size-controlled dissolution of silver nanoparticles at neutral and acidic pH conditions: Kinetics and size changes. Environ. Sci. Technol. 2014, 48, 11954-11961. [CrossRef] [PubMed]

25. Ma, R.; Levard, C.; Marinakos, S.M.; Cheng, Y.; Liu, J.; Michel, F.M.; Brown, G.E., Jr.; Lowry, G.V. Size-controlled dissolution of organic-coated silver nanoparticles. Environ. Sci. Technol. 2011, 46, 752-759. [CrossRef] [PubMed]

26. Isaacs, M.A.; Durndell, L.J.; Hilton, A.C.; Olivi, L.; Parlett, C.M.; Wilson, K.; Lee, A.F. Tunable Ag@ Sio 2 core-shell nanocomposites for broad spectrum antibacterial applications. RSC Adv. 2017, 7, 23342-23347. [CrossRef]

27. Morones-Ramirez, J.R.; Winkler, J.A.; Spina, C.S.; Collins, J.J. Silver enhances antibiotic activity against gram-negative bacteria. Sci. Transl. Med. 2013, 5, 190ra81. [CrossRef] [PubMed]

28. Dhainaut, J.; Dacquin, J.-P.; Lee, A.F.; Wilson, K. Hierarchical macroporous-mesoporous SBA-15 sulfonic acid catalysts for biodiesel synthesis. Green Chem. 2010, 12, 296-303. [CrossRef]

29. Zhao, D.; Huo, Q.; Feng, J.; Chmelka, B.F.; Stucky, G.D. Nonionic triblock and star diblock copolymer and oligomeric surfactant syntheses of highly ordered, hydrothermally stable, mesoporous silica structures. J. Am. Chem. Soc. 1998, 120, 6024-6036. [CrossRef]

30. Landau, M.V.; Dafa, E.; Kaliya, M.L.; Sen, T.; Herskowitz, M. Mesoporous alumina catalytic material prepared by grafting wide-pore MCM-41 with an alumina multilayer. Microporous Mesoporous Mater. 2001, 49, 65-81. [CrossRef]

31. Parlett, C.M.A.; Durndell, L.J.; Machado, A.; Cibin, G.; Bruce, D.W.; Hondow, N.S.; Wilson, K.; Lee, A.F. Alumina-grafted SBA-15 as a high performance support for Pd-catalysed cinnamyl alcohol selective oxidation. Catal. Today 2014, 229, 46-55. [CrossRef]

32. Guo, X.-C.; Dong, P. Multistep coating of thick titania layers on monodisperse silica nanospheres. Langmuir 1999, 15, 5535-5540. [CrossRef]

33. NIST. Binding Energies of Ag 3d 5/2. Available online: https://srdata.nist.gov/xps/EngElmSrchQuery. aspx?EType=PE\&CSOpt=Retri_ex_dat\&Elm=Ag (accessed on 6 July 2017).

34. Gaarenstroom, S.W.; Winograd, N. Initial and final state effects in the esca spectra of cadmium and silver oxides. J. Chem. Phys. 1977, 67, 3500-3506. [CrossRef]

35. Weaver, J.F.; Hoflund, G.B. Surface characterization study of the thermal decomposition of ago. J. Phys. Chem. 1994, 98, 8519-8524. [CrossRef]

36. Waterhouse, G.I.N.; Bowmaker, G.A.; Metson, J.B. Oxidation of a polycrystalline silver foil by reaction with ozone. Appl. Surf. Sci. 2001, 183, 191-204. [CrossRef]

37. Nanda, K.; Maisels, A.; Kruis, F.; Fissan, H.; Stappert, S. Higher surface energy of free nanoparticles. Phys. Rev. Lett. 2003, 91, 106102. [CrossRef] [PubMed]

38. Jiawei, W.; Wenxing, C.; Chuanyi, J.; Lirong, Z.; Juncai, D.; Xusheng, Z.; Yu, W.; Wensheng, Y.; Chen, C.; Qing, P.; et al. Defect effects on $\mathrm{TiO}_{2}$ nanosheets: Stabilizing single atomic site au and promoting catalytic properties. Adv. Mater. 2018, 30, 1705369.

39. Nolan, M.; Iwaszuk, A.; Lucid, A.K.; Carey, J.J.; Fronzi, M. Design of novel visible light active photocatalyst materials: Surface modified $\mathrm{TiO}_{2}$. Adv. Mater. 2016, 28, 5425-5446. [CrossRef] [PubMed] 
40. Yu, J.; Zhou, W.; Xiong, T.; Wang, A.; Chen, S.; Chu, B. Enhanced electrocatalytic activity of Co@N-doped carbon nanotubes by ultrasmall defect-rich $\mathrm{TiO}_{2}$ nanoparticles for hydrogen evolution reaction. Nano Res. 2017, 10, 2599-2609. [CrossRef]

41. Bhattacharyya, K.; Danon, A.; Vijayan, B.K.; Gray, K.A.; Stair, P.C.; Weitz, E. Role of the surface lewis acid and base sites in the adsorption of $\mathrm{CO}_{2}$ on titania nanotubes and platinized titania nanotubes: An in situ FT-IR study. J. Phys. Chem. C 2013, 117, 12661-12678. [CrossRef]

42. Xu, C.; Liu, Y.; Huang, B.; Li, H.; Qin, X.; Zhang, X.; Dai, Y. Preparation, characterization, and photocatalytic properties of silver carbonate. Appl. Surf. Sci. 2011, 257, 8732-8736. [CrossRef]

43. Slager, T.; Lindgren, B.; Mallmann, A.J.; Greenler, R.G. Infrared spectra of the oxides and carbonates of silver. J. Phys. Chem. 1972, 76, 940-943. [CrossRef]

44. Vaudreuil, S.; Bousmina, M.; Kaliaguine, S.; Bonneviot, L. Synthesis of macrostructured silica by sedimentation-aggregation. Adv. Mater. 2001, 13, 1310-1312. [CrossRef]

45. Kokubo, T.; Kushitani, H.; Sakka, S.; Kitsugi, T.; Yamamuro, T. Solutions able to reproduce in vivo surface-structure changes in bioactive glass-ceramic A-W³. J. Biomed. Mater. Res. 1990, 24, 721-734. [CrossRef] [PubMed]

(C) 2018 by the authors. Licensee MDPI, Basel, Switzerland. This article is an open access article distributed under the terms and conditions of the Creative Commons Attribution (CC BY) license (http:/ / creativecommons.org/licenses/by/4.0/). 